\title{
An Analysis of the Conversational Implicatures in Bishop's Poetry
}

\author{
Yuan Li
}

\begin{abstract}
This paper attempts to draw on Grice's cooperative principles as a stylistic device to demonstrate the thematic meaning and the aesthetic effects emerged in the conversational implicatures in Bishop's poetry, particularly North Haven and Insomnia. Applying linguistic theory as a tool to investigate poetry, this paper suggests an innovative approach: a pragmastylistic approach to illustrate literary works. Revealing the relation between Bishop's violation of cooperative principles including quantity maxim, quality maxim, relation maxim, and manner maxim in specific lines of poetry, and the creation of conversational implicatures, it clarifies the author's connotation underlying the superficial expressions and enables readers to understand the theme in a profound way. By means of developing a particular approach of availing of linguistic principles to demonstrate poetic language, this paper sets up a general scheme to interpret poetry in a stylistic perspective, and sheds light on a multidisciplinary path to explore other literary texts.
\end{abstract}

Index Terms-Bishop, cooperative principle, North Haven, Insomnia, pragmastylistics.

\section{INTRODUCTION}

"All too often it is felt that the studies of language and literature, in English departments and elsewhere, pursue divergent paths, each under its own momentum, and fail to cohere within a single discipline" [1]. Countless research studies have been carried out within the linguistic field or literary branch respectively, rather than in one interdisciplinary coherently and complementarily. Leech, as one of the pioneers in settling this "lang.-lit." problem, argues that "the literature cannot be examined in any depth apart from the language, any more than the language can be studied apart from the literature... a literary work cannot be properly understood without a thorough knowledge of the language which is its medium of expression" [1].

Pragmatic literary stylistics is developing within the framework of a broader range of work which has been termed the "cognitive humanities" (examples of work in this area include: Turner 1998, 2006; Hogan 2003; Palmer 2004, 2010) [2]-[6]. Like other areas of the cognitive humanities, pragmatic literary stylistics draws on a number of more established fields. Stylistics is an interdisciplinary enterprise which involves applying ideas from linguistics in the study of how texts are produced, understood and evaluated, and in addressing theoretical questions associated with this. It

Manuscript received September 21, 2016; revised March 20, 2017. This paper is sponsored by CSC (China Scholarship Council), No. 201508210242.

Yuan Li is with the School of Foreign Languages, Peking University, Peking, China (e-mail: potialiy@sina.cn). necessarily has many branches, both because of the wide range of genres, modes and purposes of the texts that are the object of study for stylistics, and because of the variety of frameworks from linguistics within which they can be analyzed. Pragmatic literary stylistics is one such branch [7].

Apart from the abundant already existing research on Bishop's poetry which universally adopt literary theory to demonstrate it, this paper aims to emerge as the medium which merges literature and linguistics, specifically, apply Grice's cooperative principles to the interpretation of Bishop's poetry, particularly the two poems North Haven and Insomnia. It portrays how Bishop violates the cooperative principles in specific poetry and what performance is created by the conversational implicatures. This process expresses the author's connotation beyond the superficial stanzas, reveals the beauty and mystery of the poetic language, and finally facilities readers' understanding of the profound themes.

\section{COOPERATIVE PRINCIPLES}

Grice in his Logic and Conversation analyzes cooperation as involving Four Maxims: Quantity, Quality, Relation, and Manner. Speakers give enough and not too much information to accord the maxim of quantity. They are genuine and sincere, speaking truth or facts to meet the maxim of quality. Utterances are relative to the context of the speech to fill the maxim of relation. Speakers try to present meaning clearly and concisely, avoiding ambiguity to satisfy the maxim of manner [8]. His cooperative principle is based on the assumption that language users tacitly agree to cooperate by making their contributions to the talk as is required by the current stage of the talk or the direction into which it develops.

Grice further defined Four Maxims as follows:

Quantity: a contribution should be as informative as is required for the conversation to proceed. It should be neither too little nor too much.

A. Make your contribution as informative as is required.

$B$. Do not make your contribution more informative than is required.

Quality: speakers should be truthful. They should not say what they think is false, or make statements for which they have no evidence.

A. Do not say what you believe to be false.

$B$. Do not say that for which you lack adequate evidence.

Relation: speakers' contributions should relate clearly to the purpose of the exchange. That is to say, participants should speak out something to be relevant to topic.

Manner: speakers' contributions should be perspicuous.

A. Avoid obscurity of expression. 


\section{B. Avoid ambiguity.}

C. Be brief.

D. Be orderly [8].

Grice suggests that if the speaker violates one of the maxims above deliberately, some conversational implicature will inevitably be invented and delivered to the hearer. As regard to Bishop's poetry, Bishop is the speaker who talks to her readers while she is writing, and she sometimes violates some maxim to impart on the hearers certain underlying meaning. The following section will probe into a handful of typical poems in which the palpable violation generates pregnant conversational implicatures.

\section{III.ANALYSIS OF CONVERSATIONAL IMPLICATURES IN BISHOP'S POETRY}

This section introduces Bishop's North Haven and Insomnia as a model on which the analysis of maxim violations and the interpretation of conversational implicatures are exemplified [9].

\section{A. Conversational Implicatures in North Haven}

North Haven is a world renowned poem in which Bishop sincerely delineates her grief for her friend Robert Lowell. In this process, she encodes a host of writing strategies of violating maxims to enliven the atmosphere and diversify the narration. The following exemplifications, in italicized letters, grouped in four maxims respectively, are fruitful and rewarding for exploiting the theme profoundly.

1) Violation of the Maxim of Quantity

I can make out a rigging of a schooner

a mile off; I can count

the new cones on the spruce. It is so still

the pale bay wears a milky skin, the sky

no clouds, except for one long, carded horse's-tail.

At the onset of the poem, Bishop portrays a good deal of details what she later described to Frank Bidart as "a feeling of intensely quiet meditation" from which one may construct a natural meditation of some sort [10]. Palpably, among massive detailed descriptions of the equal salience, one image is foreground in the picture, i.e., a "carded horse's-tail". "Carding" is the separation of wool into strands in preparation for spinning. It is apparent that surplus depiction of the clouds has been given compared to the other images in the same stanza. At this point, the sub-maxim of the quantity maxim is violated, i.e., Do not make your contribution more informative than is required. The conversational implicature generated by this over description can be drawn as follows: a "carded horse's-tail", the tiny strip of cloud appears in the almost no-cloud sky, just as Bishop's memory and grief towards a close friend comes up in such a quiet, calm and clear day. This implicature also paves the way for the unfolding of their story in the following stanzas.

The islands haven't shifted since last summer,

even if I like to pretend they have

--drifting, in a dreamy sort of way,

a little north, a little south or sidewise,

and that they're free within the blue frontiers of bay.

This month, our favorite one is full of flowers:

Buttercups, Red Clover, Purple Vetch, Hawkweed still burning, Daisies pied, Eyebright,

\section{the Fragrant Bedstraw's incandescent stars,}

and more, returned, to paint the meadows with delight.

Two apparent over depictions in these two stanzas can be traced: the imaginative, unrealistic multi-directional movements of islands, and the detailed lists of precise names of flowers. The islands actually haven't moved at all but Bishop not only imagines them to move, but also speak out the exact directions: "a little north, a little south" until unspeakable direction "or sidewise". As for the flowers, the list occupies the whole stanza and ends up with an endless expression "and more". All these extra description leads readers to the same conversational implicature: The days without Robert Lowell are torturing and unbearable. The standstill of the islands symbolizes Bishop's vacant life after Lowell's death. The cease of Lowell's life results in the halt of Bishop's happy life. How she wishes the islands can move again, her life is enlivened, and Lowell can come back! She has no choice but to focus on the types of flowers which were blooming exactly the same in the old days when Lowell were here. It seems to Bishop that the more complex names she can remember and tell, the more memory she can draw from the same place, from the same objects, and more comfortable she can feel. The grief is overwhelming from the conversational implicatures.

Years ago, you told me it was here

(in 1932?) you first "discovered girls"

and learned to sail, and learned to kiss.

You said "such fun", you said, that classic summer.

("Fun" - it always seemed to leave you at loss...)

In this stanza, a conspicuous year, along with a question mark, is presented in the bracket. There's no necessity to state the exact number of the year, especially after the time information "Years ago" at the onset of this stanza, to cause repetition. Rather, Bishop cannot remember the year clearly so she forces herself to recall and adds a question mark to assure the correctness. What does this violation of quantity imply? Bishop misses Lowell so much that she endeavors to clarify all the detailed information pertinent to him, hoping to bring back the old blissful days.

... and that they're free within the blue frontiers of bay...

....afloat in mystic blue...

This example, different from the previous ones, is composed of two lines respectively from the beginning stanza and the ending stanza. The first emergence of the word "blue" may be the poet's need of narration, but the repeated use of it later, especially in the case that the second blue is a noun which is stressed by being modified by an adjective "mystic" and being transformed from a concrete word to an abstract one, inevitably forms a deliberate violation of quantity maxim which triggers readers' inference about the connotation meaning of the color blue: grief, sorrow, lament.

2) Violation of the Maxim of Quality

I can make out a rigging of a schooner a mile off; I can count

the new cones on the spruce. It is so still

the pale bay wears a milky skin, the sky

no clouds, except for one long, carded horse's-tail.

The quality maxim argues that "speakers should be truthful. They should not say what they think is false, or make 
statements for which they have no evidence." According to common sense, no one make out a rigging of a schooner a mile off, or count the new cones on the spruce. Bishop here is declaring some statements beyond her capacity. Given the context that North Haven is the place teeming with her memory with Robert Lowell, it's reasonable to assume that Bishop is attempting to indicate the implicature that she can't be more familiar with this place. She knows every single object, every subtle change, only because she used to spend endless sweet times with her intimate friend in this scene. This implicature naturally orientates to the succeeding display: despite the scene remains the same, her friend has gone forever. She has almost all the identical factors under view except the most vital one, Robert Lowell.

3) Violation of the Maxim of Relation

You left North Haven, anchored in its rock,

afloat in mystic blue... And now-you've left

for good. You can't derange, or re-arrange,

your poems again. (But the Sparrows can their song.)

The words won't change again. Sad friend, you cannot change.

This stanza adopts the second personal pronoun "you" to directly address Robert Lowell and deliver Bishop's utterances. However, among the repeated statements concerning Lowell, one inserted sentence regarding the sparrows comes into readers' sight. As the relation maxim says: speakers' contributions should relate clearly to the purpose of the exchange. That is to say participants should speak out something to be relevant to topic. The quick shuttle here from Lowell to sparrows and back to Lowell seems irrelevant superficially, but thoroughly its conversational implicature forms a comparison between the past and the present, between the dead and the alive, which enhances the miserable grief towards the dead. The sparrows' continuous song reminds Bishop's memory of Lowell's revision in every minute.

\section{4) Violation of the Maxim of Manner}

The Goldfinches are back, or others like them, and the White-Throated Sparrow's five-note song,

pleading and pleading, brings tears to the eyes.

Nature repeats herself, or almost does:

\section{repeat, repeat, repeat; revise, revise, revise.}

One sub-maxim of Manner maxim requires being brief. The last line of this stanza consists of two words which both repeat three times. The lexical meaning of the word "repeat" and "revise", as is displayed in the morphological prefix "re-", indicates repetition inherently. However, Bishop is not satisfied with this level so she goes one step further, i.e., repeat the word itself to accelerate the "repetitious performance." The implicature emerges here may be inferred as Bishop's emphasis of this identical and regular cycle of nature's evolvement. But some scholars argue that this patterned cycle of nature reminds Bishop of the patterned cycle of Lowell's creative life which is "repeat, repeat, repeat; revise, revise, revise." Given this background knowledge, one extra implicature invented here is Bishop's worries towards Lowell's painful and unnatural process of revision of his poems.

You left North Haven, anchored in its rock, afloat in mystic blue... And now-you've left

for good. You can't derange, or re-arrange,

your poems again. (But the Sparrows can their song.)

The words won't change again. Sad friend, you cannot change.

The final stanza has witnessed three times' repetition of the same proposition meaning "dead people can't change their work again." The first statement contains two similar but slightly divergent words: "derange" and "re-arrange", which form a pair of repetition themselves. The second statement replaces the subject "you" in the first statement with the object "words (poems)". The last sentence also makes some change by calling the addressee "sad friend". Nonetheless, Bishop is delivering the same thing. This obvious violation of Briefing maxim definitely gives birth to Bishop's affirmation of Lowell's incapability of revision. If we take Bishop's negative attitude towards Lowell's notorious revisions of his published works, more conversational implicatures can be targeted. Bishop's attitude toward Lowell's revisions is emphatically suggested by the allusion to Love's Labor's Lost; Lowell's at best neutral and at worst destructive penchant for revision is, in Bishop's eyes, labor lost. Bishop's attitude is further explained in her 1934 Vassar essay "Gerard Manley Hopkins": "The poem, unique and perfect, seems to be separate from the conscious mind." Thomas Travisano suggests that Bishop's idea that a poem is an objective artifact separate from consciousness is responsible for her own refusal to revise after publication [11]. Continually revising a poem, Bishop seems to say, destroys it. Therefore, the violation of Briefing maxim in both two stanzas indicates more implicatures than Bishop's stress of the nature's cycle pattern and her recognition of Lowell's frozen revision. It is suggested that Bishop loathes Lowell's infamous labor-lost revision on the published works, which destroys the poems.

\section{B. Conversational implicatures in Insomnia}

Insomnia is one of Bishop's most outstanding poems in which Bishop contemplates a "world" inverted where the facts of reality are transformed [9]. In this sense, the maxim of quality is inevitably violated. This section scrutinizes the details of all types of maxim violation in this displacement of perspective.

1) Violation of the Maxim of Quantity

where left is always right,

where the shadows are really the body,

where we stay awake all night,

where the heavens are shallow as the sea

At the end of the poem, Bishop lists a great deal of descriptions of an imaginary place. In order to constitute an anti-reality world, Bishop violates the maxim of quantity to create enough facts for readers to catch up with her imagination. Her aim of violating and listing is to invent an inverted world in the poetry, which serves as the prerequisite for her revealing of the most theme-related sentence: "and you love me". Readers' understanding towards the truth value of this sentence is somehow inverted by these previous four descriptions which violate the maxim of quantity and generate the conversational implicature of an inverted world.

2) Violation of the Maxim of Quality 


\section{The moon in the bureau mirror}

\section{looks out a million miles}

Throughout the poem, Bishop is violating the maxim of quality, speaking of moon as a human being, to unfold the following scenes. Using personification is palpably one way of violating quality maxim, for endowing the inanimate objects with thoughts, movements, emotions is undoubtedly a way of depicting against reality.

she'd tell it to go to hell,

and she'd find a body of water,

or a mirror, on which to dwell.

So wrap up care in a cobweb

and drop it down the well

In the following stanza, Bishop continues to violate the quality maxim and give more verb acts to moon. Actually, the moon is the author herself. Bishop is adopting an implied way to express herself, that is, to remove her thoughts and actions of to the moon. The speaker's loneliness is projected on the moon that helps her to wrap up her care in a cobweb and drop down the well.

\section{(and perhaps with pride, at herself,}

\section{but she never, never smiles)}

far and away beyond sleep, or

\section{perhaps she's a daytime sleeper}

Two "perhaps" emerge in this stanza post a sharp question whether or not here is also a violation of quality. The lexical meaning of "perhaps" contains the situation that the speaker lacks evidence on what he is making statements. In this respect, it is plausible to say that the employment of this word succeeds to save the poet from violating the quality maxim. However, the truth is whether adding "perhaps" or not will never shake the fact that the maxim is absolutely violated. In the first sentence, Bishop lacks evidence on the statement that the moon is with pride or not, rather than the moon is animate nor not. No matter the moon is proud or arrogant, she is endowed with human being's emotion, and this is the violation of quality maxim. In the second example, Bishop is not sure whether the moon is a daytime sleeper. Even if the moon is not, Bishop is talking about it as if she is alive and needs some sleep sometime. Given the two examples here, the conclusion may be drawn that "perhaps" does offer more than one options in some situation, and sometimes can avoid violating quality maxim, but if all the options involved are apparently false, then no matter how many choices "perhaps" may offer, the sentence is violating the quality maxim in a higher level.

3) Violation of the Maxim of Relation

\section{where left is always right,}

where the shadows are really the body,

where we stay awake all night,

\section{where the heavens are shallow as the sea}

The previous section has examined how this stanza has violated the maxim of quantity. This section argues that at the same time it violates the maxim of relation. These four lines introduce four pairs of antonyms: left and right, shadow and body, day and night, heaven and sea. The four categories which have no natural relationship to each other are bounded in one stanza only to perform the function of reinforcing the reader's acceptance of an inverted world.

4) Violation of the Maxim of Manner

\section{where the heavens are shallow as the sea}

Is now deep, and you love me.

One sub-maxim of the manner maxim requires that the speaker should avoid ambiguity in the utterance. The last utterance of Bishop can be interpreted in two countervailing ways depending on the place to add reader's own comma. One way of adding the comma is:

\section{where the heavens are shallow,}

as the sea is now deep,

and you love me.

The first interpretation unfolds like this: In the inverted world, the heavens which are deep in reality are now shallow, and the sea which is shallow in reality is now deep. This phenomenon conforms to the preceding inverted phenomena. The inverted world is proved to be inverted on all aspects. This sentence works as the readers' springboard to the interpreting of the next theme line "and you love me." Based on the observation that all object, concepts, and thoughts are supposed to be observed in the inverted approach, we have to understand the utterance "you love me" in the opposite way: "you don't love me."

Contrarily, if we put the "comma" in another place, the whole understanding will be reversed.

where the heavens are shallow as the sea,

is now deep,

\section{and you love me.}

This interpretation view the first two lines as only one object rather than two. There is only one existing object heaven, which is compared to sea to exemplify how shallow it is. But the shallow heaven in the inverted world is not shallow anymore. The word "now" emerges here to mark the change, and stress the abnormal phenomenon: the heavens, which should presumably also be shallow due to the inverted world, is remaining deep now. They have estranged and diverged from the previous inverted series. The inverted world is inverted again and now exactly like the reality. On the basis of this situation, the theme line "and you love me." can be literally understood as "you really love me".

Bishop in this last stanza, which delivers the theme of the poem, presents the readers two opposite ways of interpreting the utterance "you love me." Her violation of manner maxim, being ambiguous, offers readers' more than one option to internalize the theme in one's own way. In the first sight of this stanza, one may find it's a complex sentence to be understood. This is the game Bishop weaved in this poem: ambiguity arouses abundant interpretations, meditations, and interests.

\section{CONCLUSION}

Pragmastylistics is a brand new inter-discipline which aims to combine the divergent paths of language study and literature study, specifically, to apply linguistic theory to analyze the language in literature work. Following this momentum, this paper drew on linguist Grice's cooperative principles to illustrate the aesthetic effects of the language in Bishop's poetry, particularly, North Haven and Insomnia. It investigates how the poet violated the cooperative principles while creating the poetry, what sorts of conversational 
implicatures sprang from the violation, and also how these conversational implicatures contribute to readers' understanding certain underlying meaning or themes of the poems. Different from the numerous already published studies on Bishop's poetry which examine specific literary theory, this paper exploited a fresh approach to interpret literary texts, through which readers can digest the beauty and mystery of the poetic language in a new sense, discover the connotation behind the superficial expressions, and generate new understanding towards the profound theme. In sum, this paper pioneered a frame to study poetry in a stylistic angle, and shed light on the inter-discipline of literature study.

\section{ACKNOWLEDGMENT}

My highest thanks go to my tutor, Professor Margaret Harper in University of Limerick, for her extraordinary expertise, beneficial suggestions, patient instruction and huge encouragement. I thank her for leading me, a student whose major is linguistics, into the splendid world of poetry, and set on a journey towards an interdisciplinary study Pragmastylistics.

I also wish to express my gratefulness to Peking University (in which I am studying now) for the financial support.

\section{REFERENCES}

[1] G. N. Leech, A Linguistic Guide to English Poetry, London: Longman, p. 2, 2014.

[2] M. Turner, The Literary Mind: The Origins of Thought and Language, Oxford: Oxford University Press, 1998.
[3] M. Turner, The Artful Mind: Cognitive Science and the Riddle of Human Creativity, Oxford: Oxford University Press, 2006.

[4] P. C. Hogan, Cognitive Science, Literature, and the Art: A Guide for Humanists, London: Routledge, 2003.

[5] A. Palmer, Fictional Minds, Lincoln: University of Nebraska Press, 2004

[6] A. Palmer, Social Minds in the Novel, Columbus: Ohio State University Press, 2010.

[7] S. Chapman and B. Ed. Clark, Pragmatic Literary Stylistics, New York: Palgrave Macmillan, 2014.

[8] H. P. Grice, "Logic and conversation," in Syntax and Semantics, P. Cole and J. Morgan, Eds. New York: Academic Press, vol. 3, p. 45, p. 47, 1975.

[9] E. Bishop, Poems, London: Chatto \& Windus, p. 68, pp. 210-211, 2011.

[10] E. Bishop, One Art: Letters, R. Giroux. Ed. New York: Farrar Strauss Giroux, p. 624, 1994

[11] T. Travisano, Elizabeth Bishop: Her Artistic Development, Charlottesville: University of Virginia Press, pp. 100-101, 1989.

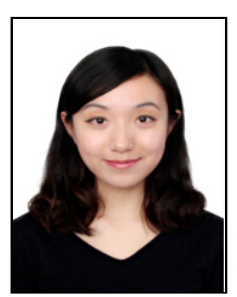

Yuan Li was born in Shanghai, China in 1990, she is now with the School of Foreign Languages, Peking University, Peking, China. She is now a master student specializing in pragmastylistics.

She was sent abroad for further study at the government's expenses in 2016, sponsored by CSC (China Scholarship Council), No. 201508210242. Her current and previous research interests include stylistics, Groarke Vona's poem.

Ms. Yuan worked as a Student Ambassador when she studied in University of Limerick. She was also a committee member in the most renowned society in UL - International Society. Her position there is PRO (Promotion). 